\title{
LOS ORÍGENES DE LA ESTÉTICA DE LO COTIDIANO. JoHN DeWeY y LA NOCIÓN De EXPERIENCIA ESTÉTICA
}

\author{
THE ORIGINS OF THE AESTHETICS OF THE QUOTIDIAN. JOHN \\ DEWEY AND THE NOTION OF AESTHETIC EXPERIENCE \\ Gloria LuQue Moya* \\ Universidad de Málaga, España. glorialm@uma.es \\ ReCibido El 5 de FEBRERO DE 2019, APROBADO EL 30 DE JULIO DE 2019
}

\begin{abstract}
Resumen
La estética de lo cotidiano es una nueva área de investigación que trata de trascender el limitado enfoque que había caracterizado a la estética moderna, reconociendo la continuidad entre las bellas artes y otros aspectos de la vida y reclamando el carácter estético de nuestra vida diaria. Los orígenes de este movimiento, que surge como una crítica a las instituciones y a las teorías ilustradas, pueden rastrearse en el pragmatismo de John Dewey y su noción de experiencia estética. El filósofo prepara el camino para la estética de lo cotidiano al situar el carácter estético en la experiencia, en lugar de en objetos o en situaciones específicas. Este trabajo considera la noción deweyana de experiencia estética, ofreciendo una nueva aproximación desde la cual actualizar su estética. Para ello, analizaré las principales cualidades que definen el término, evidenciando su potencial para superar las críticas de Yuriko Saito.
\end{abstract}

\section{Palabras clave}

Dewey, experiencia estética, vida cotidiana, ritmo, Saito.

\section{Abstract}

The aesthetics of the quotidian is a new research field that attempts to overcome the limited approach that had characterized modern aesthetics, recognizing the continuity between the fine arts and other aspects of life and claiming the aesthetic dimension of our daily life. The origins of this movement, which started out as a critique of institutions and enlightened theories can be traced to the pragmatism of John Dewey and his notion of aesthetic experience. The philosopher paves the way for the aesthetics of the quotidian by placing the aesthetic character in the experience rather than in objects or specific situations. This article considers the Deweyan notion of aesthetic experience, offering a new approach from which his aesthetics can be updated. For this purpose, the main qualities which define the term are analyzed, showing their potential to overcome Yuriko Saito's criticism.

\section{KeY WORDS}

Dewey, Aesthetic Experience, Everyday Life, Rhythm, Saito.

* (D) orcid.org/0000-0002-7626-3961 Google Scholar 


\section{Introducción}

En las últimas décadas hemos asistido al nacimiento y desarrollo de la estética de lo cotidiano como un intento de superación de la tradición moderna, la cual había confinado la investigación estética a los encuentros con las obras de arte. Esta nueva área intenta ampliar el enfoque limitado que había caracterizado a esta disciplina, reconociendo la continuidad entre las bellas artes y la vida ordinaria y reclamando el carácter estético de nuestra cotidianeidad. De este modo, el objeto de la estética ya no se restringe exclusivamente a las obras de arte o a la naturaleza, sino que trata de dar cabida a una gama más amplia de experiencias humanas de todas las tradiciones culturales.

Asimismo, como ha evidenciado Yuriko Saito, la estética de lo cotidiano también ha introducido dentro de su objeto de estudio cuestiones teóricas que no habían recibido una atención adecuada por parte de la estética occidental. (Saito, Aesthetics). Estas van desde el anonimato de la autoría en los objetos cotidianos o la ausencia de una identidad determinada del objeto de experiencia estética, hasta el resultado pragmático de los objetos o los compromisos que las personas adquieren cuando realizan determinadas actividades. El interés por ampliar el discurso estético imperante, incluyendo objetos, cualidades y valores que no tuvieron cabida previamente, ha generado una creciente literatura que trata de atender a esta nueva corriente desde un enfoque sistemático y en profundidad.

La pujanza que ha cobrado la estética de lo cotidiano en la escena intelectual explica la revitalización de la estética de John Dewey y su obra El arte como experiencia (1934). El filósofo estadounidense fue uno de los predecesores históricos que ha inspirado a teóricos contemporáneos en mayor o menor medida y ha sido considerado por algunos especialistas de lo cotidiano como el abuelo de la sub-disciplina. (Leddy, The Extraordinary 44; Berleant 164; Sartwell 761; Haapala 40). Su visionaria propuesta trató de restaurar la continuidad entre la estética y los procesos vitales a partir de un renovado concepto de experiencia estética que, a diferencia de las tradiciones analíticas, prescinde del método y del pensamiento científico, así como su insistencia en conceptos duales para desplegarse en un ámbito más amplio.

Dewey partirá de una visión crítica que rechaza los problemas de museificación y compartimentalización del arte que han obstaculizado 
$\mathrm{y}$, de hecho, escinden las denominadas bellas artes de los procesos ordinarios de nuestras vidas:

[...] se impone una primera tarea para el que pretende escribir sobre la filosofía de las bellas artes. Esta tarea consiste en restaurar la continuidad entre las formas refinadas e intensas de la experiencia que son las obras de arte, y los acontecimientos, hechos y sufrimientos diarios, que se reconocen universalmente como constitutivos de la experiencia. (Dewey, El arte como experiencia 3-4)

Las páginas que siguen pretenden abordar la noción de experiencia estética, prestando una especial atención a las cualidades que la definen como un proceso que se despliega en la vida. De este modo, en primer lugar se situará dicha noción dentro del proyecto filosófico deweyano, ya que su propuesta naturalista proporciona la base biológica y los fundamentos antropológicos desde los cuales restaurar la continuidad entre las prácticas estéticas y los procesos cotidianos. En segundo lugar, se atenderá a las principales cualidades que definen la experiencia estética, ofreciendo una nueva aproximación desde la cual actualizar la estética deweyana. Posteriormente, se revisará la crítica que Yuriko Saito ha realizado en nuestros días a la noción deweyana de experiencia, apuntando cómo esta se fundamenta en una interpretación diferente de lo cotidiano.

\section{La experiencia estética como proceso}

La noción de experiencia estética deweyana es un término complejo que ha recibido numerosas críticas desde que Dewey trató de definirla en El arte como experiencia hasta nuestros días (Pepper 389; Croce 203). Algunos especialistas de la filosofía de Dewey, como Thomas Alexander, han destacado en este respecto que para comprender su noción de experiencia estética hay que situarla dentro de su gran proyecto filosófico (Alexander, The Human Eros 4). En la misma línea, Arnold Berleant ha destacado que esta noción y su obra El arte como experiencia (1934) resultan la mejor introducción a su filosofía como un todo (Berleant 159). Berleant reivindica el legado que esta obra deja a la estética contemporánea y la considera desde el proyecto filosófico en el que surge, la propuesta pragmatista desarrollada en diferentes dominios que van desde la metafísica, la epistemología, la lógica, la ética o la filosofía política y social (Berleant 159-160). 
En oposición a la tradición occidental, la cual había distinguido la experiencia estética de la vida real, restringiéndola a un ámbito separado como museos, galerías, teatros o salas de conciertos, la estética de Dewey se sitúa desde un punto de partida diferente, el naturalismo. La cualidad estética de la experiencia denota un proceso el cual no está limitado a eventos o individuos aislados, sino que puede implicar a cualquier persona en cualquier momento de su vida. Esto es, conlleva una conciencia sensitiva del y con el medio; por ello, en palaras de Arnold Berleant, Dewey puede ser considerado uno de los precursores del creciente interés en la estética de la vida cotidiana (Berleant 164).

Ahora bien, no todas las experiencias son experiencias estéticas. Dewey distinguirá la experiencia que ocurre continuamente en el proceso vital de la experiencia estética o "una experiencia". La investigación actual ha atendido a este aspecto siguiendo el tercer capítulo de El arte como experiencia (1934), titulado "Cómo se tiene una experiencia", pero es necesario considerarla dentro de su naturalismo cultural. Según este, los seres humanos en su interacción con el medio están constantemente ampliando sus horizontes de significado. Sin embargo, la experiencia estética será la más completa e inclusiva, aquella que implica un proceso de crecimiento en el que los seres humanos crean nuevos significados y alcanzan una nueva armonía con el medio. En palabras de Dewey:

\begin{abstract}
[...] lo estético no es una intrusión ajena a la experiencia, ya sea por medio de un lujo vano o una idealidad trascendente, sino que es el desarrollo intenso y clarificado de los rasgos que pertenecen a toda experiencia completa y normal. Considero que este hecho es la única base segura para construir la teoría estética. (Dewey, El arte como experiencia 51-52)
\end{abstract}

La cita provee dos aspectos clave a considerar. En primer lugar, lo estético no supone un lujo o una idealidad trascendente, sino que tiene sus raíces en la vida y será una cualidad esencial de nuestro proceso cotidiano. Como ha destacado Arnold Berleant, Dewey propone una noción de experiencia estética que supone una participación directa e íntima en el contexto de las situaciones (Berleant 164-165). La experiencia estética nos permite ampliar, de este modo, los límites de la estética tradicional e incluir otros dominios y aspectos de la vida. Para Dewey, toda experiencia es potencialmente estética; por ello, como subraya Thomas Leddy, la experiencia estética de lo cotidiano hay que situarla en 
nuestros desplazamientos diarios, en el lugar de trabajo, en los centros de compras y lugares de entretenimiento (Leddy, The Nature 3).

En segundo lugar, en contraste con la estética moderna, atribuye la cualidad estética a la experiencia no a los objetos. Esto es, a diferencia de la estética moderna, la cual había desarrollado una teoría que trataba con las características estéticas de objetos típicamente definidos como obras de arte, para Dewey los objetos son parte del proceso de la experiencia. Así leemos en El arte como experiencia (1934): “En tales experiencias cada parte sucesiva fluye libremente sin junturas ni vacíos hacia las partes que las continúan." (Dewey, El arte como experiencia 42) Es decir, no solo cualquier objeto puede ser experimentado estéticamente, sino que este es un elemento de ese proceso en el que todas las partes confluyen y tienen un papel esencial.

Esta aproximación muestra un abismo con la teoría contemplativa que la estética había desarrollado, pues distinguía entre la experiencia estética y la ordinaria, limitando los encuentros propiamente estéticos a lugares limitados como museos y galerías. Dewey, en cambio, desde el primer capítulo de El arte como experiencia (1934) reivindica que las propias obras de arte tienen su origen último en el mundo de la vida. Los seres humanos superan los factores de oposición y conflicto en el continuo devenir cotidiano, y estas respuestas creativas conllevan una vida más significativa. De este modo, no está reduciendo la cualidad estética a una mera lucha orgánica, sino identificando nuestro trasfondo orgánico como las raíces de la estética. Así, dirá Dewey: “Estos lugares comunes biológicos son algo más que eso; llegan hasta las raíces de lo estético en la experiencia." (Dewey, El arte como experiencia 15).

Ahora bien, no todas las cosas que experimentamos constituyen "una experiencia". En nuestra vida diaria encontramos distracción y dispersión; por este motivo, sólo tenemos una experiencia estética, cuando el proceso llega a su fin. En palabras de Dewey: "En contraste con tal experiencia, tenemos una experiencia cuando el material experimentado sigue su curso hasta su cumplimiento" (Dewey, El arte como experiencia 41). La experiencia estética es un acto completo que ocurre en nuestras vidas cuando estamos más vivos y concentrados en nuestra implicación (engagement) con el medio. Lo que la distingue de otras es ese proceso que revela el significado del encuentro humano en el mundo. 
A continuación paso a considerar las características que Dewey adscribe a la experiencia estética como proceso. El autor no ofrece una lista precisa de estas, pero sí que trata sobre estos aspectos a lo largo de El arte como experiencia (1934). Dichas cualidades nos permiten situar la experiencia estética en la cotidianeidad y dan un papel primario a la facultad creativa en nuestras interacciones con el medio.

\section{a) La unidad de la experiencia estética}

La primera cualidad que caracteriza la experiencia es la unidad que le da su nombre. Dewey define la experiencia estética como un proceso que confluye en un todo único y auto-suficiente, pese a las diferentes fases y etapas del proceso. Es decir, "[...] tenemos una experiencia cuando el material experimentado sigue su curso hasta su cumplimiento" (Dewey, El arte como experiencia 41). Por ello, la experiencia estética no puede reducirse a un hecho aislado, sino que emerge en nuestra cotidianeidad cuando se da esa unidad y cierre del proceso. No obstante, Dewey advierte que dicho cierre no hay que malinterpretarlo como mero cesar. En "una experiencia" la conclusión no es meramente un final, sino un momento que conduce a la culminación. Es el resultado de un proceso organizativo, el cual revela el significado del encuentro humano con el mundo.

Es importante destacar en este respecto que el filósofo estadounidense introduce dicha unidad como una cualidad que impregna todas las partes pese a las variantes entre las mismas. De este modo, las experiencias estéticas tienen pausas o silencios, pero no rupturas o huecos. "La existencia de esta unidad" -dirá Dewey- "está constituida por una cualidad determinada que impregna la experiencia entera a pesar de la variación de sus partes constituyentes" (Dewey, El arte como experiencia 43). Esto es, la unidad no se puede reducir a la previsión o anticipación del cierre o el fin, como recientemente ha defendido Sherri Irvin (Irvin 33), sino que se trata de una cualidad organizativa que se desarrolla en los diferentes eventos del proceso como un todo. Son organizaciones temporales en las que cada fase es parte del proceso, aunque el todo solo pueda ser intuido o sentido. La experiencia estética, caracterizada por la indeterminación de su análisis, alcanza la consumación cuando es experimentada como un todo, cuando fluye de un punto a otro; esto es, se trata de un proceso con diferentes partes a través de las cuales la criatura viva va desplegando su potencial para significar su existencia inmediata. 
Las situaciones en las que emerge la experiencia humana son existenciales e históricas, sin embargo, será en la experiencia estética donde todas las fases confluyan y el hombre se vincule creativamente con el mundo. El filósofo pone el énfasis en esta unidad que, como ha puesto de relieve Thomas Alexander, no será conocida o comprendida, sino que habrá que sentirla (Alexander, John Dewey's Theory 202). La experiencia estética, por tanto, posee una unidad diferenciada a partir de la cual el hombre desplegará la capacidad creativa para crear nuevas formas de interacción, nuevos significados ${ }^{1}$. Se trata de un proceso con diferentes elementos que confluirán con un ritmo acompasado hasta su culminación.

\section{b) El ritmo como esquema universal}

Tradicionalmente la investigación sobre la obra de Dewey no ha prestado suficiente atención a esta cualidad y su explicación ha dependido de la noción de "forma". Sin embargo, el ritmo sustenta la actividad estética en la cotidianeidad, ya que será el esquema universal que esté detrás de toda organización en los cambios y actividades que se den (Dewey, El arte como experiencia 169). El mundo de la vida no es mero flujo, explica Rosa Fernández (85), sino que todas las interacciones que afectan la estabilidad y el orden en el flujo del cambio son ritmos. El ritmo es, por tanto, una propiedad de la criatura viva, pero también de la naturaleza. Los seres humanos se ven afectados por los ritmos naturales, desde el amanecer hasta el atardecer, así como sus propios ritmos internos.

Dewey se ocupará de esta cualidad en los capítulos siete y ocho de El arte como experiencia (1934), titulados "La historia natural de la forma" y "La organización de energías". Comienza realizando una genealogía de la interacción del ser humano con el medio a través de este flujo: en un principio, el hombre, siendo consciente de los ritmos de la naturaleza, se hace granjero y relaciona estos ciclos rítmicos con sus necesidades y la vida en comunidad; posteriormente, cuando los seres humanos introdujeron nuevos modelos económicos, el hombre generó nuevos ritmos, nuevas formas de interacción con el medio. En otras palabras, la íntima participación del hombre en los ritmos naturales le induce a introducir ritmos donde no existían; y esto es la actividad estética en

\footnotetext{
${ }^{1}$ En su propuesta contemporánea Arnold Berleant ha recuperado esta cualidad para su noción de "aesthetic engagement", poniendo de relieve la integración de elementos que se produce en la experiencia estética. Berleant explicará que dicha integración no sólo implica la unión de diferentes factores, sino la fusión de diferentes modos sensoriales (Berleant 47).
} 
germen (Dewey, El arte como experiencia 167). El hombre no se conformó con adaptarse a los cambios naturales, sino que los usó para dar armonía y orden a ese mundo, para celebrar sus relaciones con la naturaleza:

\begin{abstract}
Entonces los ritmos de la naturaleza captados se emplearon para introducir un orden evidente en alguna fase de las observaciones e imágenes confusas de la humanidad. El hombre ya no conformaba sus actividades necesariamente a los cambios rítmicos de ciclos naturales, sino que usaba los que le imponía la necesidad, para celebrar sus relaciones con la naturaleza, como si esta le hubiera conferido la libertad de su reino. (Dewey, El arte como experiencia 167)
\end{abstract}

De este modo, el ritmo no se limita estrictamente a una fase del producto del arte, sino que se presenta como la armonización acompasada que preside la interacción con nuestro medio. La clave reside, pues, en la dependencia del desarrollo de las producciones estéticas con la existencia de ritmos en la naturaleza, los cuales proporcionarán las condiciones para la aparición de la forma estética:

No obstante, el naturalismo en arte significa algo más que
la necesidad común a todas las artes, de emplear medios
naturales y sensuales; significa que todo lo que puede
expresarse es algún aspecto de la relación del hombre y su
ambiente, y que este tema alcanza su más perfecto maridaje
con la forma, cuando dependemos de los ritmos básicos que
caracterizan la interacción de ambos y nos abandonamos
con confianza. (Dewey, El arte como experiencia 171)

Los hombres se sirven, por tanto, de los ritmos naturales como modelos para crear nuevas formas de interacción y para explicarlo Dewey recurrirá a la noción griega de techné. La filosofía occidental había asociado dicho término con un tipo de conocimiento y actividad interesada, unida a la necesidad. Por el contrario, según el filósofo estadounidense, la techné es una reproducción del orden de los cambios naturales. A través de esta los griegos unieron las cosas creadas con los ritmos del cuerpo, llegando a constituir lo que más tarde se llamarían bellas artes.

Por ello, los ritmos muestran por qué la separación entre vida y teoría estética es aparente e impuesta. No hay distinción, sino una continuidad y este tipo de división es convencional y artificial. Los ritmos no son solo una fase del producto artístico, sino el modelo que sirve de guía para 
realizar la armonización que se busca en nuestra constante interacción con el medio. Es decir, el ritmo implica una variación constante y esto será un coeficiente indispensable para que se despliegue el orden estético (Dewey, El arte como experiencia 185).

La experiencia estética es el modo rítmico de interacción con el medio y, aunque algunas críticas han enfatizado la separación entre lo cotidiano y este tipo de experiencias, Dewey resalta que no se trata de un hecho aislado. La vida supone energía y atención, pero también ritmo y movimiento, es un proceso de interacción e intercambio a través del cual el hombre dinámicamente organiza su medio. Por esa razón, Dewey da el mismo valor al cambio y al orden; de hecho, si hay un gran cambio o variación, más interesante será la respuesta estética. En cada momento, la criatura viva está en interacción con el medio, pero será en la inmediatez de las situaciones donde el hombre experimentará el mundo y organice las energías, implicando las experiencias pasadas y creando nuevos significados. A través de la noción de ritmo se admite que no existe una formula fija, sino que estamos en un proceso con final abierto, que está en continua auto-renovación.

\section{c) La organización de energías}

Inevitablemente, pensar la noción de ritmo en John Dewey nos conduce a la noción de forma. El autor la define como la organización de los materiales naturales a través de una asimilación propia, la cual conduce a nuevos y distintivos significados. Ahora bien, dicha organización no será estática o estable sino una configuración dinámica, en cuanto que va desarrollándose y rehaciéndose en el continuo acontecer de la vida, a través de esas tensiones y situaciones de conflicto que nos afligen constantemente. La forma no es un mero organizador de elementos en una estructura ordenada, sino la totalidad de dicha organización.

La cualidad que caracterizara esta configuración u organización de energías será la creatividad, pero también su carácter vital y funcional. Se trata del modo en el que el hombre puede experimentar una vida consumada y este proceso no cesa, estar vivo implica crear nuevas relaciones en diferentes contextos con diferentes consecuencias. Cada fase, cada conclusión, incluso cada pausa, son partes importantes de esa configuración. Así, aunque aprendemos a interaccionar con el medio a través de la cultura, la emergencia de nuevas situaciones conlleva la creación de organizaciones, las cuales pueden llegar a 
ser formas estéticas si se dan una serie de condiciones y posee unas cualidades específicas que se consideran a continuación.

La primera característica que describe la noción deweyana de forma es que se trata de un orden o configuración dinámica. Esto es, dicha organización no será estática o estable, sino que va desarrollándose y rehaciéndose continuamente. Para Dewey las cualidades que llegan a través de los órganos de los sentidos no son directamente experimentadas, sino que el hombre las organiza rítmicamente. Él advierte que William James con su psicología ya condenó y derrumbó esta bifurcación e intentó destacar cómo numerosas obras de artes en sí mismas también lo habían desmentido (Dewey, El arte como experiencia 134).

Así pues, en lugar de centrar la atención en viejos dualismos, que en numerosas ocasiones conducían a callejones sin salida, Dewey pone su acento en esa relación o conexión entre las partes, tradicionalmente separadas en materia y forma o en sensación y significado. Su noción de forma engloba todo ese tipo de términos porque se presenta como la respuesta ordenada, la reorganización y la reintegración del hombre con su medio durante el proceso vital. En palabras del propio autor, “La forma puede ser definida como la operación de fuerzas que llevan la experiencia de un acontecimiento, objeto, escena y situación hacia su propio cumplimiento integral" (Dewey, El arte como experiencia 154). Podría decirse, según Alexander, que Dewey presenta una teoría radical de la forma interpretada funcionalmente, similar a la de la obra de arte ya que no se trata solo de una ordenación de materia, sino de una configuración dinámica realizada desde una temporalidad propia (Alexander, John Dewey's Theory XX).

La segunda cualidad clave será la idea de continuidad, según la cual la forma no es una mera ordenación de hechos en el que se apilan experiencias. Para explicarlo Dewey recurre a la tragedia griega como ejemplo de esta organización de eventos. Este tipo de teatro se constituye por un comienzo, un medio y un fin donde la argumentación debe estar organizada en la trama, no dispuesta al azar. Tampoco puede ser fruto de la casualidad, sino que ordena las diferentes actuaciones en una serie continuada de actos. Al igual que Aristóteles, advierte un punto importante: que el argumento no es unitario sino que concierne a un solo ser, a un único proceso. En palabras de Aristóteles: 
Con todo, el elemento más importante de todos es la trama de los hechos; pues la tragedia es imitación no de personas, sino de acción y de vida, y la felicidad y la infelicidad están en la acción, y el objetivo es un tipo de acción, no la calidad. (Aristóteles 49)

Para Dewey lo valioso de la tragedia es la organización de las acciones. La imitación es imitación de una única acción o cosa, sin embargo la forma proporciona una organización, un ajuste, una sucesión continuada que nos presenta el conjunto. Así la función del poeta no consiste en narrar lo que ha sucedido sino lo que podría suceder, lo posible conforme a lo verosímil y lo necesario. En contraposición, los malos poetas serán aquellos que utilicen los argumentos o las acciones simples. Los argumentos más hermosos son los que no parecen que sucedan por azar, sino que se han realizado intencionadamente. El poder peculiar de la tragedia, dirá Dewey, consiste en dejarnos al final con un sentido de reconciliación más que de horror (Dewey, El arte como experiencia 108)

Esto nos conduce a la última cualidad, la anticipación. Para Dewey las condiciones de la noción de forma serán la continuidad, la conservación, pero también la tensión y la anticipación. En palabras del propio autor: "Sin tensión interna habría un ímpetu fluido hacia un límite inmediato; no habría nada que pudiera llamarse desarrollo y cumplimiento" (Dewey, El arte como experiencia 155). La resistencia es un momento necesario que traerá aparejada la superación de problemas mediante la creación de nuevos modelos de integración. Por ello, la fase consumada de la experiencia siempre presenta algo nuevo (Dewey, El arte como experiencia 156). Ese giro inesperado será un aspecto esencial que no implicará una mera resolución mecánica sino la mirada puesta en el futuro, el enfoque ante futuras resistencias con las que uno se pueda encontrar.

Este aspecto se entiende si tenemos en cuenta que la forma tiene que ser definida en términos de relación; esto es, aludiendo al carácter activo, dinámico y energético de la noción de forma. La forma irá proponiendo múltiples finales que se irán adoptando según las situaciones que emerjan. Por ello, el papel de la experiencia estética será servir a la vida, más que prescribir un modo de vida definido y limitado; y las condiciones que lo hacen posible son la tensión y la contingencia. 
Dewey dedicará especial atención a la tensión, ya que posibilitará las nuevas formas en el desarrollo del proceso vital y artístico. Ante la resistencia, la criatura viva rehace sus experiencias pasadas integrándolas en un nuevo momento en el que ni nos quedamos anclados en el pasado, ni producimos una respuesta mecánica, sino que generamos algo nuevo: "El pintor y el poeta, como el investigador científico, conoce las delicias del descubrimiento" (Dewey, El arte como experiencia 157)

Por tanto, introduce orden y armonía pero también la necesidad de variedad y de novedad. En palabras del autor: "La demanda de la variedad es la manifestación del hecho de que estando vivos tratamos de vivir, hasta que somos intimidados por el temor o entontecidos por la rutina. La necesidad misma de la vida nos empuja hacia lo desconocido." (Dewey, El arte como experiencia 191). La forma es el proceso energético de organización del material de la experiencia, fundado, significado, un suceso consumado que no trasciende la vida sino que la actualiza completamente:

Solamente se conserva lo que se mueve hacia adelante; de
otra manera hay una detención y un rompimiento. Por esta
razón la consumación es relativa; en vez de ocurrir de una
vez por todas en un punto dado, es recurrente. El término
final se anticipa por pausas rítmicas de manera que este fin
es definitivo solamente de una manera externa. (Dewey 155)

La organización de energías, pues, no se impone como una estructura definitiva, sino que más bien habrá que entenderla como un proceso que no acaba. La forma es esa organización dinámica que hace que una experiencia pueda ser considerada y recordada como tal. Por ello, para Dewey descubrir la naturaleza de la forma será idéntico a descubrir lo que supone que la experiencia sea llevada hasta su cumplimiento o consumación. Ahora bien, ¿qué tipo de actitud u orientación caracteriza esa organización de energías? Este aspecto será la última característica clave que se tratará en la siguiente sección.

\section{d) La atención plenamente consciente}

La última de las cualidades de la experiencia estética será la atención plenamente consciente (mindfulness). Ahora bien, ¿por qué este término? Dewey no utilizó esta noción que, habitualmente, se ha empleado para caracterizar prácticas procedentes de otras culturas. En esta sección 
se justificará la importancia de este tipo de atención partiendo de un análisis de la definición deweyana del término "mind" en relación con la espontaneidad y orientación que supone este tipo de experiencias.

La mejor introducción a esta cualidad de la experiencia se puede realizar citando las propias palabras del autor en relación a la noción "mente":
La mente es, en primer lugar, un verbo, Indica todas las vías para tratar consciente y expresamente las situaciones en que nos encontramos. Por desgracia, una manera influyente de pensar ha transformado los modos de acción en una sustancia subyacente que ejecuta las actividades en cuestión. (Dewey, El arte como experiencia 298)

Este texto pone de manifiesto el primer aspecto que diferencia el término deweyano: la noción "mente" no supone una sustancia fija, sino el modo $u$ orientación en el que nos encontramos en el espacio-tiempo de la situación. Él pretende superar la tradición cultural que consideraba la noción exclusivamente como verbo, limitándolo a mera sustanciación, y reduciendo las teorías estéticas a la contemplación aislada. Como ha destacado Jerry Levin, al igual que William James, Dewey no considera la mente como algo activo contra o sobre el mundo, sino como una fuerza natural, al igual que el resto, constituida por y desde un medio natural y cultural (Levin 79):

$[\ldots]$ 'mente' denota toda especie y variedad de intereses
y preocupaciones por las cosas: prácticas intelectuales y
emocionales. Nunca denota nada autosuficiente, aislado
del mundo de personas y cosas, sino que siempre se usa
respecto a situaciones, acontecimientos, objetos, personas
y grupos. (Dewey, El arte como experiencia 297)

Sin embargo, Dewey va más allá que James y, al igual que Santayana, define el término como el modo en que ponemos atención en el mundo (ya sea práctica, intelectual y emocionalmente) (Levin 79). A diferencia de la conciencia, la cual es intermitente, la noción "mente" alude a la interacción plena del hombre con el mundo. De este modo, el filósofo americano ofrece una nueva interpretación que incluye el proceso (la práctica consciente) y el resultado (la propia atención consciente). En este contexto, el término mindfulness que la psicología ha introducido en nuestros días parece recoger con mayor claridad las connotaciones que el filósofo estadounidense le atribuye. Esta noción, incluida 
recientemente dentro del ámbito académico y conceptual, define esa particular forma de prestar atención a lo que está ocurriendo en la experiencia inmediata con cuidado y discernimiento (Saphiro y Carlson 4). Para exponer esta caracterización, a continuación se presentan las tres cualidades clave que describen esta atención plenamente consciente: la intención, la atención y la actitud.

En primer lugar, la atención plenamente consciente implica orientación del proceso. Este término, ampliamente desarrollado por ScoutStroud en relación con el meliorismo deweyano, pone el acento en el proceso, no en el resultado (Stroud 392). En esa interacción constante entre organismo y medio, la orientación atenta y equilibrada permitirá la interacción absorta en las particularidades presentes de la situación.

En segundo lugar, la atención implica la completa absorción en la experiencia. Para ilustrarlo se puede recurrir al ejemplo del violinista superlativo que introduce Dewey en su obra Naturaleza humana y conducta. Según el filósofo, el violinista está completamente absorto y controla todos sus movimientos al tocar un violín. Pero esta conciencia o absorción en la actividad no supone pensamiento o inteligencia, sino que supone una exploración de la atención virtuosa (Dewey, Naturaleza humana 74-75). De manera similar, esta cualidad debe operar y darse en todas las partes de la experiencia estética. Es más, no solo debe darse, sino también ser sentida, experimentada (Dewey, El arte como experiencia 217). En la interacción con el medio, el hombre tendrá que desplegar modelos apropiados de relación y solo la atención plena en esa interacción permitirá hacer consciente al hombre de la necesidad de cambio. De este modo, cultivar la espontaneidad no consistirá en practicar una técnica en sí misma, sino en mantener la atención en la actividad.

La atención subraya la importancia de la última cualidad del término mindfulness, la actitud. Este aspecto será sumamente relevante ya que conlleva la apertura, el cuidado y la curiosidad, cualidades necesarias para que surja la espontaneidad. La experiencia estética requiere una participación con una atención sensorial, consciente, física y social. Esto es, se trata de una implicación sensorial consciente en el mundo que no solo incluye al individuo como sujeto perceptor, sino también a ese medio que le rodea y en el que está inmerso. 
En este sentido, Berleant ha enfatizado que la propuesta de Dewey supone un cambio en la teoría tradicional de la estética, ya que en ella no encontramos distinción sujeto-objeto, sino que cada uno es parte del proceso de esa experiencia (Berleant 166). Es más, la contribución activa del ser humano alejará la estética deweyana de toda doctrina de desinterés desarrollada por otras corrientes filosóficas previas. En nuestros días, Richard Shusterman ha recogido el testigo de Dewey y ha propuesto el término "conciencia somática" dentro de su disciplina somaestética (Shusterman, Pragmatist Aesthetics 267).

\section{El potencial de la estética deweyana: revisión de la crítica de Yuriko Saito}

El análisis de las características de la noción deweyana de experiencia estética ha evidenciado cómo Dewey no solo fue un precursor de la estética de lo cotidiano, sino que su noción de experiencia estética ofrece la base desde la que elaborar una teoría de la estética de lo cotidiano. Sin embargo, investigaciones recientes han considerado que el énfasis en la experiencia estética o consumada, frente a aquellas dispersas o distraídas, se fundamenta en la minusvaloración de las experiencias que se dan en la monotonía de lo cotidiano.

Es el caso de Yuriko Saito quien ha puesto de relieve que la experiencia estética deweyana es descrita en términos de unidad encapsulada, como un conjunto separado de nuestro día a día (Saito, Everyday Aesthetics 44). La autora mantiene que la interpretación de Dewey es demasiado restrictiva porque sigue adhiriendo su propuesta estética a la teoría centrista del arte. En otras palabras, según Saito, la experiencia estética finalmente es definida como una excepción a lo cotidiano, es más, tenemos que ser afortunados para que la experiencia estética ocurra.

Saito, en cambio, comienza la reflexión estética desde aquella actitud y experiencia que explora las facetas de nuestras vidas. Así, trata de ampliar y diversificar el dominio de la estética siguiendo una estrategia similar a la que propone Noël Carroll. Este autor americano intentó reunir todos los tipos de experiencias que se habían propuesto en las diversas teorías del arte. Saito da un paso más incluyendo aquellas respuestas que nos empujan a decisiones y acciones que no suponen una apreciación contemplativa (Saito, Everyday Aesthetics 11). 
Para justificar esta aproximación la autora muestra el poder e influencia de la estética en nuestras vidas diarias llegando, incluso, a determinar nuestras actitudes y acciones. Saito ofrece diversos ejemplos de diferentes tradiciones y momentos históricos para ilustrarlo: Platón y su censura a las artes; la consideración de Confucio sobre el papel que juegan los ritos para modelar a los seres humanos y la sociedad; la promoción de cierta música durante el régimen nazi en Alemania; la estética nacionalista desarrollada en Japón y EE.UU.; en la sociedad de consumo en la que vivimos, la influencia que tienen las consideraciones estéticas cuando tomamos decisiones al comprar (Saito, Everyday Aesthetics 55-56).

Saito trata, pues, de ampliar el horizonte de estudio de la estética restaurando el papel que tiene en nuestra vida cotidiana y rechazando las teorías previas. Según la autora, el estudio de la estética se había centrado en el arte generando dos modelos claramente diferenciados que excluían lo cotidiano de la reflexión estética: el primero que tomaba el arte como modelo del objeto estético; el segundo se centraba en un tipo de experiencia especial. En este contexto, pese a que Dewey trata de restaurar la continuidad arte-vida incluyendo experiencias cotidianas, expondrá Saito, su interés primario en la experiencia estética como algo especial que sobresale de la experiencia ordinaria sigue limitando la estética a un campo demasiado restrictivo (Saito, Everyday Aesthetics 44).

Aunque la crítica de Saito pone en evidencia las debilidades de la noción deweyana, su enfoque muestra deficiencias. En primer lugar, la autora examina el término "experiencia estética" desde una interpretación propia de lo cotidiano, que pone el énfasis en la normalidad de nuestro día a día. Como puso de manifiesto Richard Shusterman en la conferencia pronunciada durante el congreso con motivo de la celebración del cuarenta aniversario de la Sociedad Finesa de Estética, se han desplegado dos modos o vías para comprender la teoría de la estética de lo cotidiano. La primera enfatiza en la normalidad de lo cotidiano; mientras que la segunda subraya el carácter particular de lo cotidiano que puede ser transformado en una experiencia estética (Shusterman, "Back to the Future" 110). 
Pese a que Shusterman no lo describe explícitamente, como ha puesto de relieve Kalle Puolakka (Puolakka, "Dewey and Everyday Aesthetics")2, se puede apreciar cómo la primera de las interpretaciones ha sido explorada por autores que ponen el énfasis en la familiaridad (Arto Haapala) y los juicios cotidianos y rutinarios (Yuriko Saito); en contraposición a la segunda desarrollada por autores como Thomas Leddy quien, siguiendo a Dewey, considera lo extraordinario de lo ordinario. En este sentido, la crítica de Saito se desarrolla desde una concepción de lo cotidiano que no anula o invalida la propuesta de Dewey, sino que reflexiona sobre las facetas de la vida desde una base diferente.

En segundo lugar, al igual que otros teóricos actuales, así como contemporáneos a Dewey, Saito realiza una reflexión sobre esta noción de experiencia estética desde la lectura aislada de El arte como experiencia (1934). Sin embargo, como he tratado de evidenciar a lo largo de estas páginas, la experiencia estética debe ser considerada desde su proyecto filosófico naturalista y en oposición al discurso heredado por la tradición moderna y la estética kantiana.

La estética kantiana, como ha evidenciado Arnorld Berleant, tomaba su modelo en la objetividad racionalista y la universalidad del conocimiento científico tal y como se comprendía en el siglo XVIII (Berleant 155). Esta introdujo divisiones entre sujeto y objeto, sentido y razón, placer y gusto, interés y desinterés, etc., adscribiéndole a la noción de experiencia estética una serie de características como la universalidad, el desinterés, la objetividad y la necesidad. Sin embargo, la definición de experiencia estética cambia si consideramos a los seres humanos como seres integrales en continuo cambio, a través de esa interacción e intercambio con el medio. La noción de "experiencia estética" que Dewey propone, pues, se despliega desde un proyecto filosófico que tiene como objetivo mejorar la vida del hombre. En numerosas ocasiones Dewey expresa la creencia firme que la condición humana puede ser mejorada, y la experiencia estética tendrá un papel vital en la consecución de esa meta.

\footnotetext{
${ }^{2}$ En un artículo reciente Kalle Puolakka ha propuesto un nuevo enfoque de Dewey como esteta de lo cotidiano que supera las críticas que el filósofo norteamericano ha recibido de estetas como Yuriko Saito, poniendo su foco en la relación entre la imaginación y la experiencia estética (Puolakka, "The Aesthetics Pulse of Everyday”)
} 


\section{Conclusión}

Estas páginas han tratado de evidenciar la actualidad de la propuesta deweyana desde la estética de lo cotidiano. Dewey adopta una posición adelantada a su tiempo al mostrar la inconsistencia de la segregación entre arte y experiencia cotidiana. Desde un enfoque que incluye una combinación de raíces hegelianas y naturalismo evolucionista, una gnoseología falibilista y una orientación holística, el filósofo nos abre un universo de valiosas sugerencias sobre cómo integrar el arte en la vida. Asimismo, ofrece una noción de experiencia estética que alude al proceso a través del cual podemos crear nuevas formas significativas para desenvolvernos en el incesante quehacer vital; el proceso por el que podemos experimentar la vida con mayor plenitud.

De este modo, pese a que la noción deweyana de experiencia estética trae aparejada una serie de críticas y controversias, su propuesta puede realizar una aportación significativa a nuestros días. El análisis de las principales cualidades de este término no solo ha puesto de relieve los elementos que la componen, las cualidades y las características, sino que ha aportado una base desde la que desarrollar la estética de lo cotidiano. Esta aproximación permitirá incluir objetos o experiencias que habían quedado fuera del discurso estético, así como prácticas de otras culturas difíciles de encuadrar en los parámetros de las bellas artes, ampliando el enfoque desde el que elaborar hoy la teoría estética.

\section{REFERENCIAS BIBLIOGRÁFICAS}

Alexander, Thomas M. John Dewey's Theory of Art, Experience and Nature. The Horizons of Feelings. Albany: State University of New York Press, 1987. Print.

Alexander, Thomas M. The Human Eros: Eco-ontology and the Aesthetic of Existence. New York: Fordham University Press, 2013. Print.

Aristóteles. Poética. Trad. Alicia Villar Lecumberri. Madrid: Alianza Editorial, 2004. Print.

Berleant, Arnold. Aesthetics beyond the Arts. New and Recent Essays. Aldershot: Ashgate, 2012. Print.

Croce, Benedetto. "On the Aesthetics of Dewey". Journal of Aesthetics and Art Criticism 6(3), 1948: 203-207. Print. 
Dewey, John. El arte como experiencia. Trad. Jordi Claramonte. Barcelona: Paidós, 2008. Print.

Dewey, John. Naturaleza humana y conducta: introducción a la psicología social. Trad. Rafael Castillo Dibildox. México D.F.: Fondo de Cultura Económica, 1975. Print.

Fernández Gómez, Rosa. “Arte en la vida, artes para la vida: el ritmo de la experiencia estética". Aizpún, Teresa, Ibáñez, Cayetana y Fernández del Campo, Eva (eds.). Ritmo. El pulso del arte y de la vida. Madrid: Abada Editores, 2015. 79-90. Print

Haapala, Arto. "On the Aesthetics of the Everyday: Familiarity, Strangeness, and the Meaning of Place". Light Andrew y Smith Jonathan M. (eds.). The Aesthetics of Everyday Life. New York: Columbia University Press, 2005. 39-55. Print

Irvin, Sherri. "The Pervasiveness of the Aesthetic in Ordinary Experience". British Journal of Aesthetics. 48, 2008: 29-44. Print.

Leddy, Thomas. The Extraordinary in the Ordinary: The Aesthetics of Everyday Life. Ontario: Broadview Press, 2012. Print.

Leddy, Thomas. "The Nature of Everyday Aesthetics". Light Andrew y Smith Jonathan M. (eds.). The Aesthetics of Everyday Life. New York: Columbia University Press, 2005. 3-22. Print

Levin, Jonathan. "The Esthtetics of Pragmatism". The Poetics of Transition: Emerson, Pragmatism, \& American Literary Modernism. Durham: Duke University Press, 1999. 67-90. Print.

Liu, Yuedi y Carter, Curtis L. (eds.). Aesthetics of Everyday Life: East and West. Newcastle upon Tyne, U.K.: Cambridge Scholarship, 2014. Print.

Naukkarinen, Ossi y Saito, Yuriko (eds.). Artification, Contemporary Aesthetics, Special Volume 4, 2012. Web.

Pepper, Stephen. "Some Questions on Dewey's Esthetics". Schilpp, Paul A. (ed.). The Philosophy of John Dewey. New York: Tudor Publishing Co., 1939. 369-390. Print.

Puolakka, Kalle. "Dewey and Everyday Aesthetics. A New Look". Contemporary Aesthetics. 12, 2014. Electronic. Web 18 jul. 2019. <http://www.contempaesthetics.org/newvolume/pages/article. php?articleID=699>. 
Puolakka, Kalle. "The Aesthetics Pulse of the Everyday: Defining Dewey". Contemporary Aesthetics 13, 2015. Web 18 jul. 2019. < https:// contempaesthetics.org/newvolume/pages/article.php?articleID=730>. Saito, Yuriko. "Aesthetics of Everyday Life". The Stanford Encyclopedia of Philosophy, 2015. Web. 05 nov. 2018. <https://plato.stanford.edu/ archives/win2015/entries/aesthetics-of-everyday/>.

Saito, Yuriko. Everyday Aesthetics. Oxford: Oxford University Press, 2007. Print.

Shapiro, Shauna L. Carlson, y Linda E. The art and science of mindfulness: Integrating mindfulness into psychology and the helping professions. Washington: American Psychological Association, 2009. Print.

Sartwell, Crispin. "Aesthetics of the Everyday". Levinson, Jonathan (ed.). The Oxford Companion to Aesthetics. Oxford: Oxford University Press, 2003. 761-770. Print.

Shusterman, Richard. "Back to the Future: Aesthetics Today". The Nordic Journal of Aesthetics. 43, 2010: 104-124. Electronic. < https://doi. org/10.7146/nja.v23i43.7500>.

Shusterman, Richard. Pragmatist Aesthetics. Living Beauty, Rethinking Art. Lanham: Rowman and Littlefield Publishers, 2002. Print.

Shusterman, Richard. Thinking through the Body. Essays in Somaesthetics. Cambridge: Cambridge University Press, 2012. Print.

Stroud, Scott. John Dewey and the Artful Life: Pragmatism, Aesthetics and Morality. Pennsylvania: Pennsylvannia State University Press, 2011. Print.

\section{Como citar:}

Luque Moya, Gloria. "Los orígenes de la estética de lo cotidiano. John Dewey y la noción de experiencia estética". Discusiones Filosóficas. Jul.- Dic. 20 (35), 2019: 129-148. DOI: $10.17151 /$ difil.2019.20.35.8. 